Este artigo é o quinto transferido da AIM Magazine, a revista da Associação Italiana de Ciência e Tecnologia das Macromoléculas

(AIM) com a qual a ABPol assinou um acordo de intercâmbio em 2006 e o renovou em Janeiro desse ano.

0 artigo foi escolhido entre quatro que os editores do AlM Magazine nos propuseram. 0 autor é um pesquisador no setor das

poliamidas que colaborou com varias indústrias (italianas e brasileiras) nesse setor e conhece profundamente esse assunto. Mesmo assim, mantendo 0 estilo editorial da revista italiana ele tratou essa historia da descoberta da poliamida 66 de um jeito informativo, com pouca parte cientifica e várias notícias históricas interessantes, utilizando um estilo fluido e agradável, com alguns comentários irônicos apesar da historia ter um final trágico. 0 autor é também o Responsável Editorial do AlM Magazine.

Esse artigo foi publicado no AlM Magazine em Maio de 2010.

Ao mesmo tempo um artigo da nossa Revista, que fala de espumas políuretânicas magnetizáveis para recuperação ambiental,

foi traduzido em italiano e publicado no site da AlM Magazine em Janeiro 2012 e se encontra ao endereço:

http://www.aim.it/magazine/100-aim-magazine-febbraio-2012, com o titulo "Articolo dei brasiliani".

Tradução do mesmo autor - Cooperação: Odis Bressani Sanfilippo

\title{
Como a Poliamida Substituiu a Seda: uma História da Descoberta da Poliamida 66
}

Roberto Filippini Fantoni Consultor

Premissa: Existem muitas substâncias que fizeram a história do século XX e contribuíram para os grandes desenvolvimentos que aconteceram durante esse longo período. Muitas destas substâncias foram descobertas por acidente ("serendipity") a caminho de pesquisa diferente e existem muitos casos de que nós poderíamos mencionar em especial na área de produtos químicos e polímeros. Mas não foi exatamente assim na história do nylon que estamos para contar, porque nesse caso foi o desejo de encontrar uma alternativa para a seda, o impulso para obter um substituto daquela fibra natural maravilhosa que só a natureza é capaz de sintetizar através de sínteses tanto difícil quanto precisas e rápidas e com métodos ainda a considerar se não inatingíveis certamente ainda não alcançados. O autor desse texto, deve ao polímero do qual vamos falar a história da própria vida científico-tecnológica e, por consequência, encontra-se em uma situação psicológica que o levará a empregar demasiada ênfase, mas pelo menos com conhecimento de causa. Podemos desculpar os excessos e a extensão do texto, incomum para esta revista. Muitas das informações históricas foram encontradas na internet; outra importante fonte informativa foi um livro intitulado "Os botões de Napoleão" que fala de 17 moléculas que mudaram o mundo e o nylon é uma dessas. Esperamos que os leitores sintam-se agradavelmente envolvidos por esta história.

\section{Na Rota da Seda}

A história da seda começou a mais de 4 milênios. Segundo a lenda, foi uma concubina do imperador da China que notou que de um casulo que caiu no chá saia um fio muito fino e resistente. Outra lenda chinesa, conta que o nascimento do cultivo do bichoda-seda se deveu a uma Imperatriz chamada Xi Ling Shi (esposa do imperador Huangdi), que passeando notou uma lagarta, a tocou com um dedo e dela saiu um fio de seda! Conforme o fio saia da lagarta a Imperatriz o enrolava no dedo, obtendo uma sensação de calor. No final viu um pequeno novelo e de repente compreendeu a relação entre a lagarta e a seda.

Que tenha sido uma concubina ou uma Imperatriz fica claro que somente a intuição feminina poderia encontrar a ligação entre o bicho e a seda.
Seja como for a descoberta de que de um casulo se poderia produzir fios com comprimentos variáveis de um mínimo de $300 \mathrm{~m}$ até quase $3 \mathrm{~km}$, não é lenda o fato que a criação do bichoda-seda nasceu na China num período muito próximo a 2 milênios antes de Cristo.

Os primeiros passos foram muito lentos e as primeiras vestimentas de seda eram consideradas preciosíssimas, tanto que estavam reservadas só para a família imperial e a nobreza que a circundava. Somente muitos séculos depois foi permitido também aos ricos não nobres - os únicos que podiam pagar - usar roupa de seda.

Nos séculos sucessivos a seda foi requerida também à oeste e assim criou-se, muito lentamente mas inexoravelmente, a 
famosíssima Estrada da Seda que no período de máximo comercio entre Leste-Oeste chegou a cobrir os $10000 \mathrm{~km}$ entre Pequim e Bizâncio, Antioquia e Tiro.

Próximo ao ano zero, as cargas de seda chinesa começaram a chegar na Europa com regularidade mas a sericultura permaneceu um segredo protegido pelo chineses por ainda muitos séculos e o contrabando dos ovos do bicho-da-seda e a semente da amoreira era punido com a morte.

Narra a lenda que em 552, dois monges nestorianos esconderam ovos e sementes de amoreira numa cana de bambu vazia e chegaram a Constantinopla; assim iniciou-se a sericultura também na Europa. Lenda ou não, ficou clara a impossibilidade de manter durante tanto tempo um segredo de tal porte.

A seda, todavia, tornou-se um material valorizado e de custo elevado, que somente as classes mais abastadas e a nobreza podiam permitir-se. Durante um par de milênios a seda permaneceu um dos tecidos mais valorizados e ninguém conseguiu produzir um tecido tão belo quanto delicado: foram necessários Staudinger e a sua teoria das "grandes moléculas" para se chegar a alguma coisa semelhante à seda. Mas vamos pela ordem.

\section{A Estrutura de Seda}

A seda, como muitas fibras de origem natural, é uma proteína. A sorte desta macromolécula de proteína reside no fato de que os pendentes grupos $\mathrm{R}$ da molécula de aminoácidos que a constituem são pequenos considerando que para mais de $80 \%$ a macromolécula da seda é formada pela repetição de glicina-serina-glicina-alaninaglicina-alanina. Nos três aminoácidos constituintes da série, os grupos R são hidrogênio, metila e hidroximetila, ou seja, os menores entre todos os vinte e dois aminoácidos naturais. Este fato dá à seda a reconhecida suavidade. A presença de ligações de hidrogênio leva a grande parte do complexo macromolecular para uma estrutura de conjunção entre as diversas macromoléculas que, juntamente com a pequena dimensão dos substituintes, explica as diferentes propriedades físicas da seda que a tornam um material exclusivo: resistência à tração, fluência, brilho, cintilação. Além disso, deve-se considerar que os 15-20\% dos aminoácidos que não se encaixam nos três já mencionados anteriormente, contém grupos laterais polares que podem facilmente interagir com corantes naturais ou artificiais e assim pode-se entender como esta fibra pode ser facilmente tingida com impressionantes efeitos de cor. Em suma, podemos dizer que o acoplamento das estruturas ordenadas alternadas - que são a maioria - com estruturas mais complexas, produziu e produz uma tão grande variedade de propriedades positivas que tornam a beleza dessa fibra inigualável[ ${ }^{[1]}$.

\section{Tentativa de Imitação: os Polímeros Artificiais}

Quando a química fez grandes avanços - e referimo-nos especialmente à segunda metade do século XIX e ao primeiro quarto do século XX - as tentativas de produzir fibras de seda foram numerosas. Para citar uma tentativa mais séria, que deu o impulso às sucessivas, podemos dizer que por volta de 1880 Hilaire de Chardonnet, aluno de Pasteur, lembrou-se que tinha acompanhado o professor em Lyon para uma pesquisa sobre uma doença do bicho-da-seda. Lidando com este tópico havia passado muito tempo observando como o bicho fiava a seda ${ }^{[1]}$.

Coincidentemente, um dia em que estava trabalhando em uma câmara escura para revelar as fotos, ele notou que de uma gota da solução de colódio, caída acidentalmente em cima da mesa, podia-se "puxar" fios bastante finos. Dessa observação, passar para a tentativa de extrusar esta solução através dos buracos de uma fieira artesanal, o passo foi além de breve uma consequência

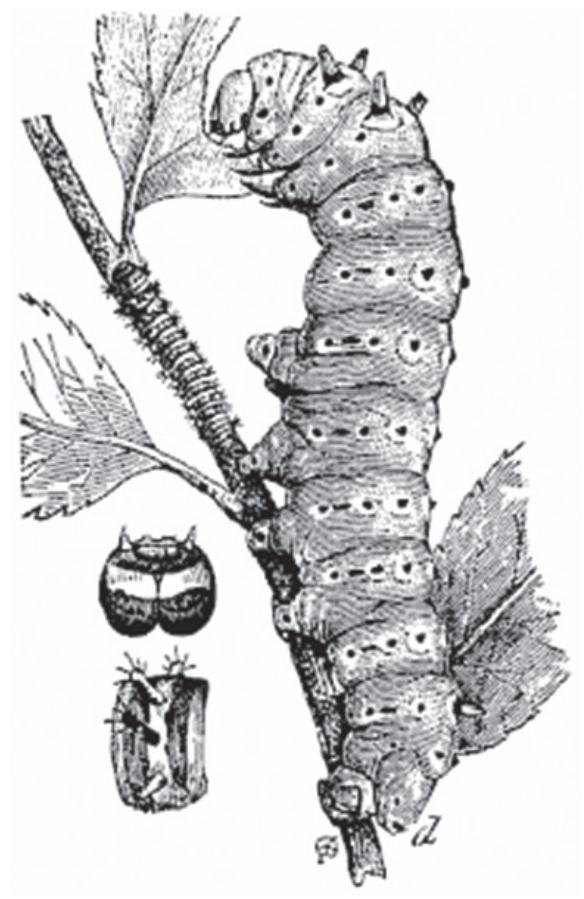

Figura 1. O bicho-da-seda.

lógica: produziu, então, os fios destinados a ser a primeira tentativa de imitação da fiação da seda: aquela que foi chamada a "seda de Chardonnet"!

Saiu um tecido excelente, durável e brilhante, mas com um defeito nao desprezível: o colódio é nitrato de celulose e é assustadoramente inflamável! Aconteceu então, inelutavelmente, que as "nobres senhoras" que começaram a usar roupas produzidas com essa "seda artificial" depararam-se com uma indesejável surpresa. Bastava que a cinza de um charuto caísse encima da roupa para produzir instantaneamente um Flash e a incineração completa do vestido: sobre o destino das mulheres as crônicas não falam. Pensando de maneira otimista, podemos dizer que levaram um tremendo susto!

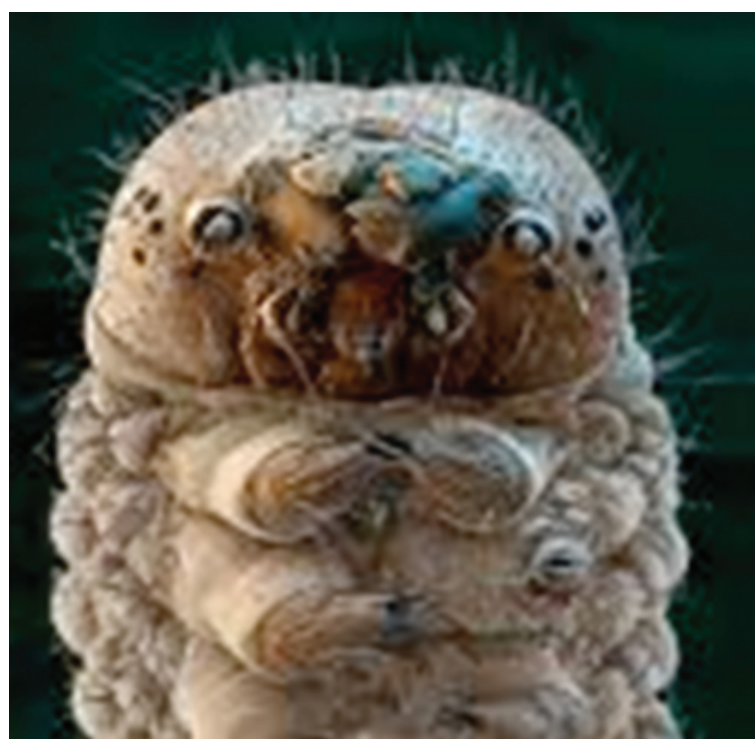

Figura 2. Cabeça do bicho-da-seda. 


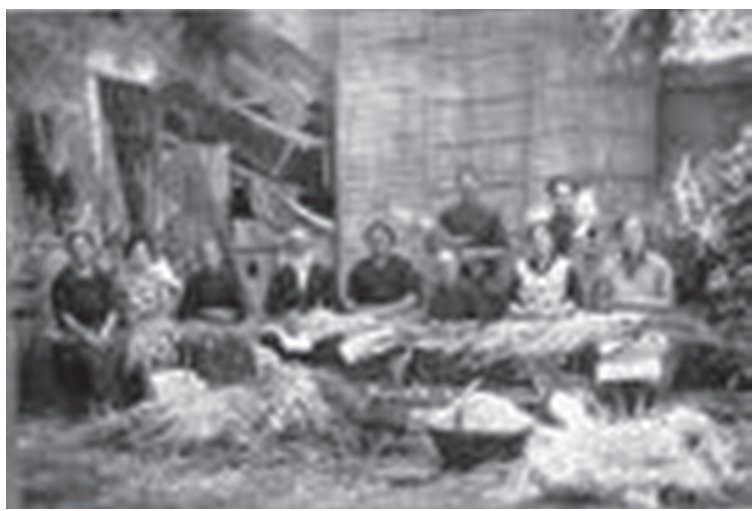

Figura 3. Uma família de camponeses trabalha o bicho-da-seda.

Ao completo fracasso seguiram várias tentativas para usar celuloses com menor teor de nitrato de celulose; finalmente, encontrando solventes adequados para a celulose, chegaram ao "rayon", com o qual se obtiveram soluções muito viscosas e fiáveis.

Desde a descoberta em 1901, na Inglaterra, passando para a primeira produção industrial de dez anos mais tarde, até chegar ao completo desenvolvimento dos anos '30, o rayon tornou-se a "seda artificial" por antonomásia, pois antes da Segunda Guerra Mundial a produção mundial ficou perto de $150 \mathrm{t} / \mathrm{ano}^{[1]}$.

\section{Polímeros Sintéticos e Intuição de Carothers}

Alteramos o cenário e dos polímeros artificiais passamos aqueles sintéticos que ao final dos anos '20 tinham já começado a desenvolver-se no mercado. Naqueles anos houve uma disputa entre os adeptos da teoria que os polímeros fossem aglomerados de moléculas e os seguidores do famoso químico alemão Staudinger que alegava serem moléculas grandes. Com esta intuição ganhou o Prêmio Nobel, só muito mais tarde em 1953, e isso demonstra que certas velhas teorias erradas são difíceis de serem substituídas, especialmente se as novas são muito vanguardistas. Uma demonstração impressionante disso foi alguns anos antes, o prêmio Nobel atribuído a Einstein por seus estudos fundamentais em fotovoltaica e não para a Teoria da Relatividade, revolucionária demais para aqueles momentos.

Portanto, o mundo dos estudiosos de polímeros estava se dividindo em duas escolas de pensamento. Entre os adeptos das ideias de Staudinger, estava Hume Wallace Carothers, um jovem químico orgânico da Harvard University ${ }^{[2]}$.

Ele foi um daqueles gênios precoces que surgem de vez em quando e que somam à própria genialidade aquela pitada de loucura que não atrapalha, ao menos que, como neste caso, leve a um fim trágico ${ }^{[3]}$ ! Seus estudos primários foram de Economia, mas depois viraram para Química - e este é um exemplo da sua versatilidade - demonstrando as próprias grandes capacidades, a fim de tornar-se, mesmo antes de se graduar, chefe do Departamento de Química e já isso parece algo impressionante ${ }^{[4]}$ !

Concluiu Mestrado e Doutorado na Universidade de Illinois e, em seguida, ensinou na Universidade de Harvard em 1924 com apenas 28 anos - onde começou a estudar as estruturas dos polímeros $^{[5]}$.

Quatro anos depois a DuPont ofereceu-lhe um cargo como Chefe da Pesquisa de um grupo cuja tarefa era as investigações fundamentais, coisa incomum para as indústrias. Inicialmente ele recusou a oferta, embora fosse muito vantajosa em termos econômicos, explicando o seguinte: "Eu sofro frequentemente de depressão e isso pode ser um problema mais sério trabalhando para vocês do que onde eu trabalho agora."

Um executivo sênior da DuPont foi para Harvard para tentar convence-lo e conseguiu ${ }^{[6,7,8,12]}$.

Em Janeiro de 1928 ele começou o primeiro trabalho com o qual pretendia obter polímeros com massa molecular maior que a máxima, até aquele momento obtido por Emil Fischer, de 4200 Dalton.

A pesquisa não foi fácil, tanto que ficou desencorajado, pois o resultado não foi obtido mesmo após dois anos. Então um seu assistente isolou o cloropreno durante a pesquisa sobre a química de polimerização do acetileno e percebeu que o produto polimerizava tornando-se um material similar a uma borracha. Nasceu portando a primeira borracha sintética: o neoprene!

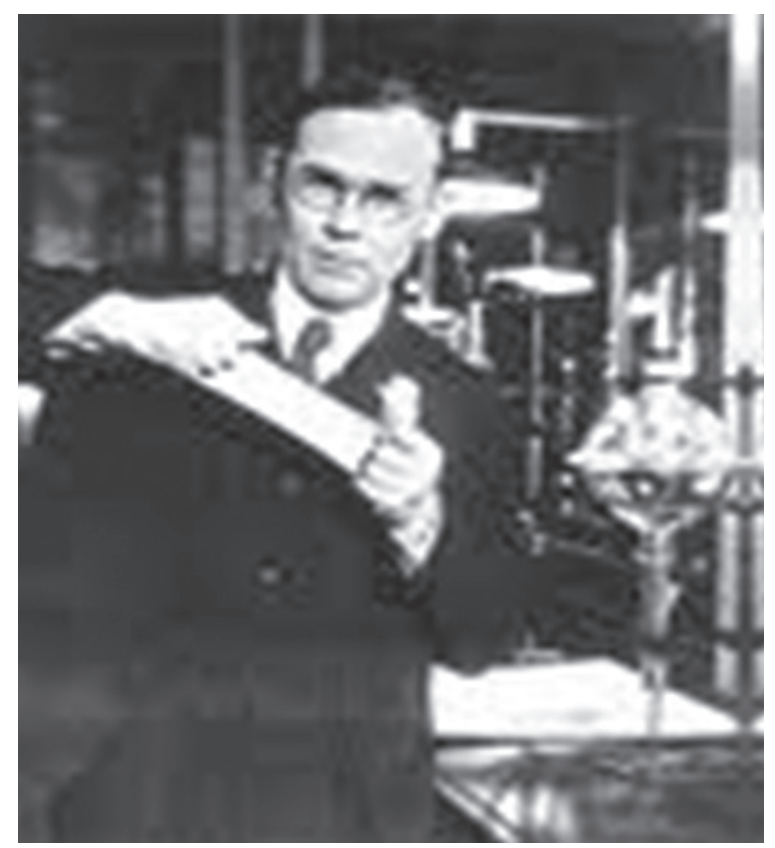

Figura 4. Carothers mostra um novo polímero.

Outros pesquisadores da equipe de Carothers estudaram a policondensação de ácidos e glicóis para obter o poliéster e em um breve tempo chegaram a obter uma massa molecular média de 12000 Dalton: eles chegaram a fiá-lo e estira-lo até obter uma fibra. A primeira fibra sintética!

Infelizmente estas fibras em água quente condensavam-se em massas pegajosas.

Aos sucessos que cada dia a mais o grupo estava obtendo, se contrapunha a depressão de Carothers que se tornava cada dia mais intensa. Ele começou a trazer comprimidos de cianeto colocados numa caixinha pendurada na corrente do relógio. Odiava preparar conferências, que o deixavam extremamente nervoso e que o constringiam a tomar álcool. Este foi o alarme do final trágico que estaria para acontecer ${ }^{[9,10,11,12]}$.

\section{O Sucesso da Poliamida e a Depressão de seu Inventor}

Depois dos poliésteres dedicou-se as poliamidas e num curto espaço de tempo polimerizou um número impressionante desses novos polímeros - mais de cem tipos de poliamidas diferentes entre os quais os responsáveis da DuPont escolheram a poliamida 66 


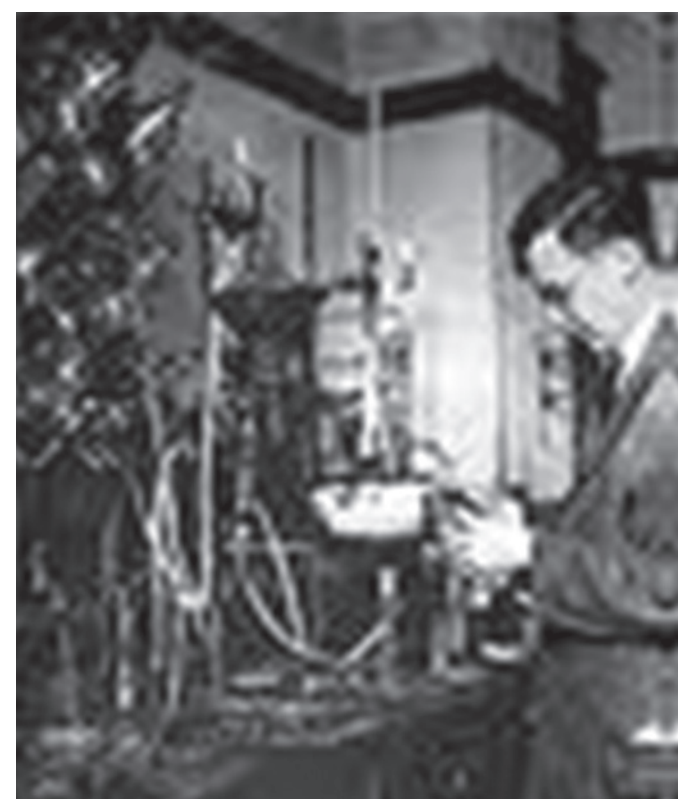

Figura 5. Carothers no laboratório.

apesar do seu alto ponto de fusão; parecia que essa tinha as melhores qualidades (alta velocidade de cristalização e alta percentagem da porção cristalina). Estávamos em 1934.

Em 1935 ele produziu meia onça deste produto.

Naqueles anos se juntou ao grupo o jovem Paul Flory (de 25 anos) que apoiou Carothers no estudo das cinéticas de poliadição e de policondensação e, como todos nos sabemos, Flory chegou a ser um dos "pais" da química macromolecular e obteve o Prêmio Nobel em 1974. Como dá para entender, tratava-se de um grupo de pesquisa de altíssimo valor do qual saíram descobertas de importância primária.

Durante este período de pesquisa proveitosa Carothers desapareceu e ninguém sabia para onde ele foi. Foi encontrado, em um hospital psiquiátrico em Baltimore, onde ela tinha ido para uma consulta sobre sua depressão galopante, tendo sido prontamente internado ${ }^{[13]}$.

Após este fato a DuPont colocou ao seu lado um outro experto pesquisador para o projeto da poliamida 66, enquanto que no desenvolvimento industrial trabalhavam dezenas de químicos e engenheiros.

Em fevereiro de '36 casou com Helen Sweetman que na DuPont trabalhava na preparação das patentes. Pouco tempo depois ele foi eleito membro da Academia das Ciências, uma honra que até então nenhum químico da indústria tinha recebido.

Mesmo assim a sua depressão agravou-se bastante o impedindo de trabalhar e, portanto foi internado por um mês em outro Instituto da Filadélfia e depois foi enviado por duas semanas aos Alpes Tiroleses, juntamente com alguns amigos. Enquanto estes últimos retornaram aos EUA ele quis ficar sozinho naquelas montanhas e não enviou notícias para ninguém, nem mesmo para sua esposa.

Foi em Setembro do mesmo ano que ele reapareceu, sem ninguém saber, sentado em sua mesa da Estação Experimental da DuPont.

Mas ele não trabalhou mais nos projetos e limitou-se apenas a visitas ocasionais.

Em Janeiro de '37 morreu de pneumonia sua irmã, a qual ele era muito ligado.

Depressão e tendência ao suicídio tornaram-se ainda mais fortes. Entre os muitos pensamentos que o empurravam ao suicídio havia aquele constante sobre a inadequação do seu trabalho de química e a escassez de sucessos. Se essa "inadequação" atraísse ao suicídio os pesquisadores dos nossos tempos, poucos seriam os "sobreviventes"!

Sobre a sua mesa encontrava-se uma lista dos químicos mais famosos que haviam cometido suicídio e antes do ato final adicionou o seu próprio nome: era o 28 de abril de 1937. No dia seguinte, em seu quarto de hotel, dissolveu no suco de limão os comprimidos de cianeto que ele sempre levava consigo: ele usou seus conhecimentos químicos para acelerar a morte pois ele sabia que uma solução ácida teria acelerado o efeito do veneno ${ }^{[14]}$.

\section{Desenvolvimento do Nylon}

As poliamidas lineares, como é a poliamida 66, têm uma estrutura básica de cadeias macromoleculares que permite fácil alinhamento dessas cadeias durante a cristalização, alinhamento que é realizado com formação do "chain folding" na parte cristalina; mas este alinhamento é reproduzível durante a estiragem, via formação de ligações de hidrogênio entre as cadeias da fase amorfa que vão gradualmente se orientando na direção da estiragem.

A grande diferença com a seda é a distância entre os grupos amídicos, pois as proteínas da seda, sendo poliamidas originadas por

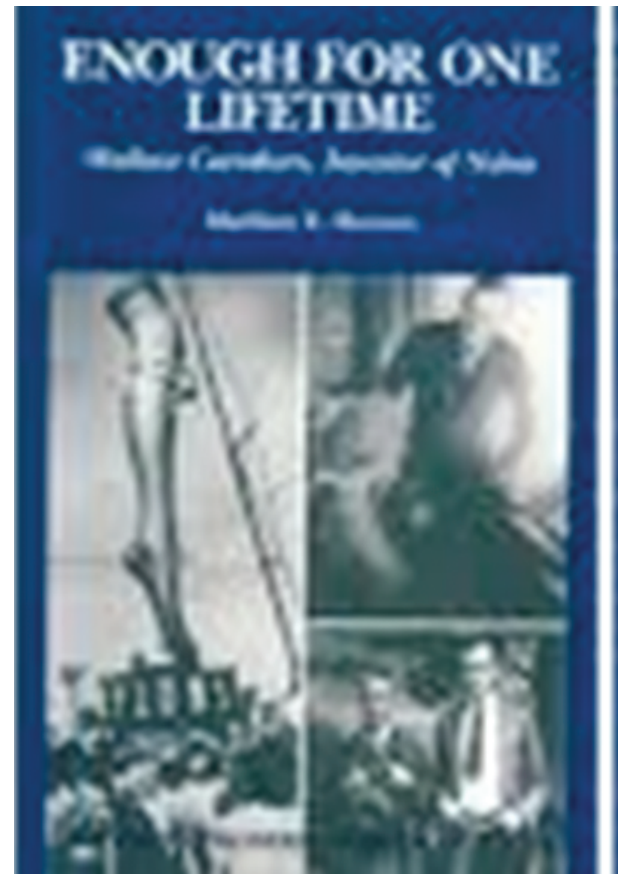

Figura 6. A capa do livro de Hermes que conta a vida de Carothers e do qual foram trazidos muitas das anedotas deste artigo.

aminoácidos naturais, têm um grupo amídico a cada dois átomos de carbono, enquanto na poliamida 66 os átomos de carbono entre um grupo amídico e o sucessivo são seis. Mas a flexibilidade dos grupos metilênicos permite à poliamida 66 de gerar um elevado número de ligações de hidrogênio seja durante a cristalização, como durante a estiragem.

Outra diferença essencial é o fato de que a seda é um tipo de poliamida $\mathrm{AB}$, onde os grupos $\mathrm{CO}$ e $\mathrm{NH}$ se alternam ao longo da cadeia, enquanto a PA66 é uma poliamida do tipo AABB, onde aos dois grupos CO seguem dois grupos NH. Seja como for, a escolha da poliamida 66 demonstrou-se ótima, mesmo com aquela pequena 


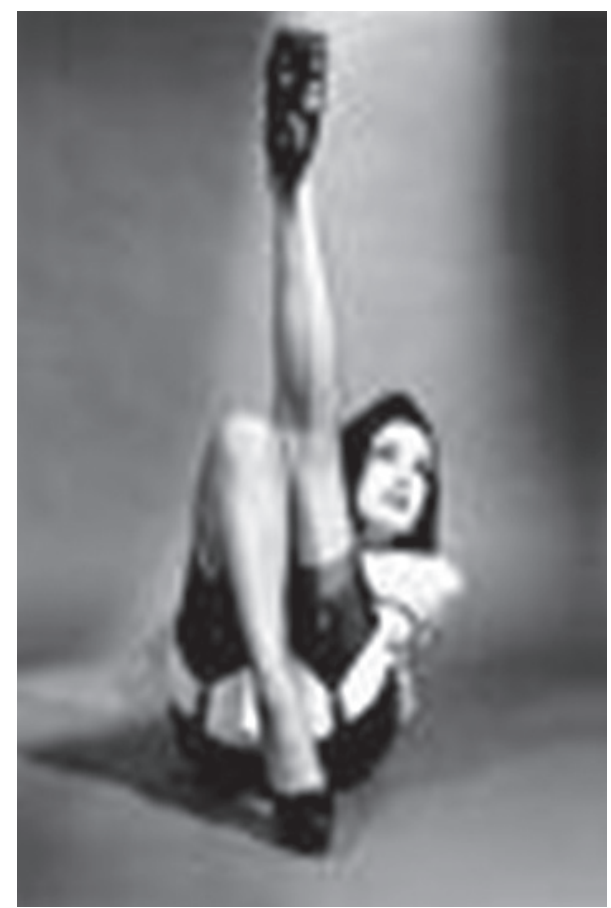

Figura 7. Um exemplo de propaganda do Nylon, logo depois da Guerra. Muito "ousado" para aquele período.

ajuda que a sorte nos dá quando temos que fazer essas escolhas. Ao final das contas a poliamida 66 foi o polímero sintético que se mostrou, mais do que outros, como o melhor substituto da seda.

Desse fato os responsáveis da DuPont aperceberam-se imediatamente e o setor do marketing trabalhou do jeito melhor para abrir inimagináveis possibilidades de mercado.

Ele saiu no mercado com o nome comercial de Nylon e este acrônimo é usado até hoje quando se fala das poliamidas em geral. Mas desse assunto iremos falar no próximo paragrafo.

A primeira aplicação foi para cerdas de escovas de dentes e o mercado dispôs delas em 1938. No ano seguinte foram as meias para mulheres a serem lançadas no mercado e a PA66 demonstrouse ideal para esta aplicação e até hoje, mais de setenta anos depois, continua a ser a melhor. Uma das mais bem sucedidas expressões desfrutadas durante a campanha de propaganda das meias foi a seguinte: "strong as steel and delicate as a spider web's" (forte como o aço e delicado como a teia da aranha). Apesar da ênfase, a comparação com as meias de seda tornou essa frase verdadeira. Nos anos ' 40 foram vendidos 64 milhões de pares de meias.

Em seguida, foram as necessidades da guerra que desfrutaram as suas propriedades. Tecidos de nylon para reforço de pneus, telas para balões meteorológicos e paraquedas, e muito mais.

Hoje a PA66 é usada em muitos setores e somente a PA6 a supera em termos de toneladas.

Carothers teria mudado de opinião se tivesse assistido a esta escalada rápida?

É difícil de dizer, porque, às vezes, aqueles que sofrem de depressão não conseguem reagir positivamente mesmo as mais otimísticas situações da própria vida.

\section{A Origem do Acrônimo Nylon}

Para concluir, poucas palavras sobre a origem desse acrônimo.

A versão mais popular durante anos estava ligada à possibilidade que o Nylon tinha dado ao Ocidente de sair da dependência da seda Japonesa, exatamente quando os eventos pré-bélicos estavam dificultando muito as relações entre os EUA e o país do Sol Nascente.

De acordo com aquela que mais tarde demonstrou-se ser uma lenda metropolitana, Nylon teria representado "Now You've Lost, Old Nippon" (Agora você perdeu meu velho japonês). Antes desta versão, tinha uma outra versão que indicava como NY-LON as iniciais das duas cidades onde o produto foi lançado em '39, o que é verdadeiro somente para Nova York, pois Londres não teve nenhum papel importante.

$\mathrm{Na}$ verdade quando estavam decidindo o nome desta nova deslumbrante fibra as propostas chegaram em grande quantidade: foram mais de 400 !

Uma das mais complicada a ser avaliada foi "Duparooh" contração de "DuPont Pulls A Rabbit Out Of Hat"; "DuPont puxou um coelho do chapéu"; certamente, para o sucesso do mercado que tinha a DuPont, o nylon foi realmente o clássico coelho que um mago puxa do chapéu, mas se eles tivessem utilizado esse horrível nome, talvez o sucesso teria sido o mesmo, mas certamente não tão rápido.

A versão mais crível para a história desse acrônimo parece ser, embora bastante complicada, a seguinte: a partir de NO-RUN, que significa nenhuma desmalhadura, e lendo-o ao contrário, você chega em NURON, que depois modificou-se em NULON e, finalmente, com uma modificação definitiva, em NYLON.

Parece mais uma história de erros tipográficos que a definição de um acrônimo, mas assim contam as diferentes histórias, e nós, pobres jornalistas, o que podemos fazer é tomar nota para depois recontá-las ${ }^{[15]}$.

\section{Conclusões}

Entre as tentativas de roubar os segredos da seda, as chamas incendiárias das sedas artificiais, a depressão e o consequente suicídio na tentativa de obter fibras sintéticas, uma pitada de sorte, grandes talentos e um monte de prospectiva, caminhamos um caminho de mais de 4000 anos em poucas páginas. Poderíamos contar muitas outras anedotas, mas temos consciência, de ter já abusado da paciência do leitor: esperamos não te-lo aborrecido em demasia e de ter mantido o seu interesse pelo menos o suficiente para sermos recompensados do esforço feito para nos documentar e escrever essa historia.

\section{Referências}

1. Couteur, P. \& Burreson, J. - "I bottoni di Napoleone", Edizioni TEA, Milano, p.112 (2008).

2. Hermes, M. - "Enough for One Lifetime, Wallace carothers the inventor of nylon", Chemical Heritage Foundation, 1996.

3. Burton, G.; Holman, J.; Lazonby, L.; Pilling, G. \& Waddington, D. - "Chemical Storylines", Heinemann Educational Publishers (2000).

4. Zumdahl, S. S. \& Zumdahl, S. A. - "Chemistry”, Houghton Mifflin Company, New York (2007).

5. Adams, R. - "A Biography", in: High Polymers: A Series of Monographs on the Chemistry, Physics and Technology of High Polymeric Substances, vol.1, Carothers on High Polymeric Substances, Interscience Publishers, New York (1940).

6. Smith; H. - Science, 229, p.436 (1985). PMID 17738664. http://dx.doi. org/10.1126/science.229.4712.436

7. Hermes, M. - "Enough for One Lifetime: Wallace carothers the inventor of nylon", Chemical Heritage Foundation, p.83.

8. Hermes, M. - "Enough for One Lifetime: Wallace carothers the inventor of nylon", Chemical Heritage Foundation, p.86. 
9. Hermes, M. - "Enough for One Lifetime: Wallace carothers the inventor of nylon", Chemical Heritage Foundation, p.140.

10. Hermes, M. - "Enough for One Lifetime: Wallace carothers the inventor of nylon", Chemical Heritage Foundation, p.135.

11. Hermes, M. - "Enough for One Lifetime: Wallace carothers the inventor of nylon", Chemical Heritage Foundation, p.144.

12. Hermes, M. - "Enough for One Lifetime: Wallace carothers the inventor of nylon", Chemical Heritage Foundation, p.157.
13. Hermes, M. - "Enough for One Lifetime: Wallace carothers the inventor of nylon", Chemical Heritage Foundation, p.197.

14. Hermes, M. - "Enough for One Lifetime: Wallace carothers the inventor of nylon", Chemical Heritage Foundation, p.291. Con citazioni prese dal Wilmington Morning News e dal New York Time del 30 Aprile 1937.

15. Fusco, O. - AIM Magazine, 56, p.34 (2002). 